\section{Electroconvulsive therapy - state of the art}

\author{
SAVITHASRI V. ERANTI and DECLAN M. MCLOUGHLIN
}

\begin{abstract}
Although electroconvulsive therapy (ECT) has been available for more than 60 years it is still the most acutely effective antidepressant treatment available (McCall, 2001). However, despite substantial advances in safety and technique, including routine use of electroencephalogram monitoring, ECT is also one of the most clinically neglected treatments in psychiatry.
\end{abstract}

\section{RATES OF USE IN THE UK AND USA}

Use of ECT is declining in the UK. In 1985 there were 137940 administrations through English National Health Service (NHS) health authorities (http://www.doh. gov.uk/public/ect_bull99.htm). In 1991 this figure had fallen to 105466 . The annual number of treatments fell even further by 1999 to an estimated 65930 , equivalent to 5.8 patients per 100000 total population. Between 1992 and 1997, the rate of ECT use in Edinburgh, UK, fell from 2.85 to 1.65 treatments per 1000 population served, mostly because of a $58 \%$ reduction in the number of recipients aged 18-65 years (Glen \& Scott, 1999). In Wales the estimated annual rate fell from 39 to 22 patients per 100000 between 1990 and 1996 (Duffett et al, 1999). Using data from the American Psychiatric Association's (APA) 1988-1989 Professional Activities Survey, Hermann et al (1995) estimated that 4.9 patients per 100000 population in US metropolitan areas received ECT annually. Interestingly, the marked reduction in ECT use in the USA during the 1970s partially reversed and then stabilised. The number of patients receiving ECT fell from 58667 in 1975 to 31514 in 1980 but by 1986, 36558 patients were being treated with ECT, although its availability had become limited in public hospitals (Thompson et al, 1994). It is not yet clear if use has stabilised in the UK and, as most ECT here is administered through the NHS, it is unlikely that such a major trend reversal will occur.

\section{VARIATIONS IN USE AND PRACTICE}

Electroconvulsive therapy standards and practice vary remarkably, not only between different countries but also within them and even within individual centres. For example, Glen \& Scott (2000) reported an 18 -fold difference in use of ECT between 11 general adult psychiatric teams within a single Edinburgh teaching hospital. An influential audit of ECT in two NHS regions in 1991 found up to 12-fold differences in use between centres, and also reported on substantial deficiencies in training and supervision (Pippard, 1992). Despite the activities of the Royal College of Psychiatrists, including publication of revised guidelines in 1995 in The ECT Handbook, only a little progress was found in a follow-up audit: just one-third of ECT clinics visited were considered to meet College standards and only one-third had suitable policies to assist trainee doctors in ECT (Duffett \& Lelliott, 1998). During 2000-2001 the Mental Health Act Commission surveyed 230 ECT facilities in England and Wales and reported that there were substantial departures from best policy, practice or training in $20 \%$ of centres (Mental Health Act Commission, 2001).

Such inconsistencies are universal. No ECT use was reported in just over one-third of the 317 metropolitan areas in the 19881989 APA survey and in the remaining areas annual rates ranged from 4 to 812 patients per 100000 population (Hermann et al, 1995). European practice is equally variable (Philpot et al, 2002). ECT is available only in specialist centres in Belgium and Germany, and limited by the availability of anaesthetic services in Latvia, Poland and Romania. ECT is prohibited in some cantons in Switzerland and, since 1994, can no longer be given in Slovenia. In Italy, where Cerletti and Bini first introduced ECT, it is effectively almost abolished, more for political than scientific reasons. Approximately $6 \%$ of patients admitted to one Japanese university hospital between 1975 and 1997 were treated with ECT but how this compares with the rest of Japan is not known (Ishimoto et al, 2000). Data on national use of ECT in developing countries are not readily available. Anecdotally, ECT seems to be commonly used in parts of India, and in some African countries practice is limited by anaesthetic resources, such that unmodified ECT is used in Nigeria (Ikeji et al, 1999).

The exact reasons for such clinical variability in ECT use in the UK and abroad are unclear. Contributing factors undoubtedly include genuine public and professional concerns about the nature of the treatment, negative and stigmatising perceptions of ECT, lack of consensus on use, resource limitations plus a certain amount of complacency and neglect on the part of psychiatrists themselves.

\section{RESEARCH IN ECT}

Does this neglect extend to research in ECT? One simple but crude measure of research activity is the number of publications on a topic. Using the Science Citation Index Expanded (available through the ISI Web of Science, http://wos. mimas.ac.uk) we examined the top ten psychiatry journals (ranked by impact factor) to identify original research articles on ECT in the past 10 years (1992-2001; search terms ECT, ELECTROCONVULSIVE and ELECTROSHOCK). We excluded reviews, editorials, single case reports and abstracts. The distribution of articles broken down by journal and country of origin is available from the authors upon request. There was a total of 117 research articles, of which about $10 \%$ were randomised controlled trials investigating the efficacy and optimal use of ECT. Preclinical studies on mechanisms of action of ECT accounted for $18 \%$ of articles. Indeed, there is an increasing amount of preclinical research on ECT being published in basic science rather than psychiatry journals. Of course, original ECT research gets disseminated through many other specialist journals, for example the quarterly Journal 
of ECT, dedicated to ECT and related topics.

The vast majority of the identified research articles emanated from North America and Europe; $47 \%$ originated from the USA, $14 \%$ from the UK and nearly $9 \%$ from Israel. Single articles were identified from Germany, Italy, Spain, Austria, Sweden, South Korea and Thailand. No articles were identified in the two specialist schizophrenia journals, although ECT has a recognised role in this condition (Fink \& Sackeim, 1996). Not surprisingly, given its remit, Biological Psychiatry published the greatest number of ECT research articles (41\% of the total). The American Journal of Psychiatry published nearly 19\%, whereas the British Journal of Psychiatry had just over $16 \%(n=19)$ of the total number.

To help put these figures into context, we also identified that during the same time period in the British Journal of Psychiatry there were 27 research articles on selective serotonin reuptake inhibitors (SSRIs) and 12 on lithium. The latter is perhaps a more appropriate comparison with ECT, given its similar duration in clinical use and level of pharmaceutical industry sponsorship. Thus, it seems that ECT-related research is being relatively well attended to. In addition, the advent of other new somatic therapies, such as repetitive transcranial magnetic stimulation and vagus nerve stimulation, is increasing interest again in ECT. We hope that some of this interest will soon transfer into clinical practice.

\section{THE FUTURE OF THE ECT CLINIC}

The current UK trend of declining ECT use could result from the introduction of newer antidepressants (particularly the SSRIs in the late 1980s), improved community care, earlier detection of mental illness and better appreciation of the indications for ECT. Assuming that some patients are not being denied an appropriate treatment, this reduction is broadly to be welcomed; however, it also has implications for standards of practice. Reduced use could be leading to diminished clinical interest, poor working knowledge and reduced effectiveness,

SAVITHASRI V. ERANTI, MRCPsych, DECLAN M. McLOUGHLIN, MRCPsych, Section of Old Age Psychiatry, Institute of Psychiatry, London, UK

Correspondence: Declan McLoughlin, Senior Lecturer, Section of Old Age Psychiatry, Institute of Psychiatry, Mailbox PO 70, De Crespigny Park, London SE5 8AF, UK. Tel: +44 (0) 78480550;

fax: 020 78480632; e-mail: d.mcloughlin@iop.kcl.ac.uk

(First received 17 January 2002, final revision 9 May 2002, accepted 16 May 2002)

further compounding the already negative public perception of ECT. The wide variations in use could also affect training. It has already been noted that some psychiatry trainees might never have the opportunity to obtain experience in ECT (Salzman, 1998).

Because ECT continues to have an established and important role in the management of treatment-resistant depression and life-threatening conditions such as depressive stupor, catatonia and neuroleptic malignant syndrome (McCall, 2001), it clearly still needs to be readily available. One possible way to overcome problems of erratic practice and haphazard training is to institute a policy of monitoring and accrediting ECT clinics as satisfying Royal College of Psychiatrists' or other internationally agreed guidelines for best practice and safety. The Scottish ECT Audit Network have reported that regular and ongoing audit, based upon predetermined national standards, appears to be successful in improving ECT practice (for further information see http://www.sean.org.uk). Alternatively, it might be more practical to develop regional specialist centres where expertise in all aspects of ECT is available. This is not an especially novel proposal: the establishment of specialist centres for other medical treatments and for the purposes of clinical training and consistency in practice and research is nowadays commonplace. As with specialist centres for cancer therapy or transplant surgery, it would be preferable that patients receive ECT under optimal conditions.

\section{DECLARATION OF INTEREST}

S.V.E. is funded by a grant from the NHS Health Technology Assessment Programme awarded to D.M.M. to research ECT.

\section{REFERENCES}

Duffett, R. \& Lelliott, P. (1998) Auditing electroconvulsive therapy. The third cycle. British Journal of Psychiatry, 172, 40I-405.

\section{_, Siegert, D. R. \& Lelliott, P. (1999)}

Electroconvulsive therapy in Wales. Psychiatric Bulletin, 23, 597-601.

Fink, M. \& Sackeim, H. A. (1996) Convulsive therapy in schizophrenia? Schizophrenia Bulletin, 22, 27-39.

Glen, T. \& Scott, A. I. F. (1999) Rates of

electroconvulsive therapy use in Edinburgh (1992-1997). Journal of Affective Disorders, 54, 8I-85.

— $\&$ _ (2000) Variation in rates of electroconvulsive therapy use among consultant teams in Edinburgh (1993-1996). Journal of Affective Disorders, 58, 75-78.

Hermann, R. C., Dorwart, R. A., Hoover, C.W., et al (1995) Variation in ECTuse in the United States. American Journal of Psychiatry, I52, 869-875.

Ikeji, O. C., Ohaeri, J. U., Osahon, R. O., et al (1999) Naturalistic comparative study of outcome and cognitive effects of unmodified electroconvulsive therapy in schizophrenia, mania and severe depression in Nigeria. East African Medical Journal, 76, 644-650.

Ishimoto, Y., Imakura, A. \& Nakayama, H. (2000) Practice of electroconvulsive therapy at University Hospital, the University of Tokushima School of Medicine, from 1975 to 1997. Journal of Medical Investigation, 47, 123-127.

McCall, W. V. (200I) Electroconvulsive therapy in the era of modern psychopharmacology. International Journal of Neuropsychopharmacology, 4, 315-324.

Mental Health Act Commission (200I) Ninth Biennial Report 1999-2001. London: Stationery Office.

Philpot, M., Treloar, A., Gormley, N., et al (2002) Barriers to the use of electroconvulsive therapy in the elderly: a European survey. European Psychiatry, 17, $41-45$.

Pippard, J. (1992) Audit of electroconvulsive treatment in two National Health Service regions. British Journal of Psychiatry, 160, 621-637.

Royal College of Psychiatrists (1995) The ECT Handbook. The Second Report of the Royal College of Psychiatrists' Special Committee on ECT (Council Report CR39). London: Royal College of Psychiatrists.

Salzman, C. (1998) ECT, research, and professional ambivalence. American Journal of Psychiatry, 155, I-2.

Thompson, J. W., Weiner, R. D. \& Myers, C. P. (1994) Use of ECT in the United States in 1975, 1980, and 1986 American Journal of Psychiatry, 15I, 1657-1661. 